\title{
EBay: \\ Towards A Perfectly Competitive Market
}

\author{
Joshua Chang, Charles Sturt University, Australia
}

\begin{abstract}
The purpose of this paper is to explain how factors in eBay create an increasingly efficient marketplace that drives it towards the conditions of a perfectly competitive market. Search and evaluation features that increase the efficiency of consumer decision making are examined and discussed in the context of information economics and market efficiency. The increased problem solving capability of consumers enabled by features in eBay show that it is moving towards a perfectly competitive marketplace. The continuous advancement of technology will further improve such market efficiencies and drive toward a perfect Internet marketplace. EBay's "near perfect' market conditions creates challenging conditions such as lowly dispersed and market driven prices, wide consumer choice, and consequently diminished advertising efforts. This implies challenges mainly in the areas of differentiation and positioning strategies by businesses to mitigate the effects of eBay's continuing shift towards perfectly competitive market conditions. It is important for businesses that are used to operating in the conditions of monopolistic competition associated with traditional market efficiencies to strategize for the upcoming challenges of near perfect market conditions facilitated by efficient market platforms such as eBay.
\end{abstract}

Keywords: Information economics, Perfect Competition, Market efficiency, EBay, Electronic Commerce, Internet business

\section{INTRODUCTION}

$\mathrm{t}$ is now well known that the Internet has provided significant search and evaluation benefits to shoppers over traditional alternatives. According to theory in the economics of information (Evans and Wurster, 1999), preceding media technologies constrain the quality and quantity of information available to shoppers. This contributes to bounded rationality issues in consumer decision making as a consequence of inferior information. Such constraints enable retailers to charge unreasonably high prices for certain items that customers do not have access to adequate price information to, and this is especially relevant with goods of international origin. Today, Internet technologies facilitate an unprecedented richness and reach of information that enhances the shopper's ability to search and evaluate merchants, products, and prices, mitigating the aforementioned problem of bounded rationality in decision making (Samuel \& Chang, 2005). Bounded rationality, according to Au \& Kauffman (2005), is defined as the limited cognitive capacity of humans in decision making when they face problem complexity under the constraints of time and lacking information.

The availability of more complete information coupled with lower entry barriers leads to the argument that the Internet provides a significant step towards a perfectly competitive market. Buyers are no longer at the mercy of retailers with unreasonably high price mark-ups as they can evaluate prices from around the world and literally purchase at the lowest possible price. Importers and retailers who have been operating on high price mark-up / arbitrage business models are expected to be disadvantaged from this development. Engendered by progressive Internet technologies, leading Internet auction site eBay is an example of an international trading platform that suggests a near perfect market where price information is easily available to all buyers and sellers. Additionally, eBay provides search and evaluation features such as reputation ratings, past buyer comments, and prices of completed transactions to help buyers make higher quality decisions. This paper explains, with theoretical 
implications, how eBay's search and evaluation features enhance consumer problem solving decisions, leading toward a perfectly competitive market.

\section{SIGNIFICANCE}

There is a paucity of research in the area of online $\mathrm{C} 2 \mathrm{C}$ auctions considering that this phenomenon is barely a decade old (Stern \& Stafford, 2005), with most research done in the area of reputation (e.g. Resnick \& Zeckhauser, 2002; Ba \& Pavlou, 2002; Dellarocas, 2003) and bidding behaviour (e.g. Dholakia \& Soltysinski, 2001; Roth \& Ockenfels, 2002; Gilkeson \& Reynolds, 2003; Stern and Stafford, 2005). The purpose of this paper is to provide a conceptual understanding of how search and evaluation features available to shoppers in eBay can improve consumer problem solving by mitigating the problem of bounded rationality, based on economic theory that assumes rational value maximisation in consumers. Information on how such benefits associated with online shopping can improve consumer problem solving would be useful to buyers for better decision making, and to retailers for improved marketing strategy formulation. This paper reviews the benefits of eBay's features according to the theory of 'Richness and Reach' by Evans and Wurster (1999), and explains how these benefits lead toward a perfectly competitive market, and tilt consumers in favour of online purchase over offline purchase. A possible limitation of this economics based approach is that $\mathrm{C} 2 \mathrm{C}$ auction bidding can be an emotional process (Smith, 1989) where bidders are likely to ignore principles of value maximization to win a coveted item at any cost (Riley \& Samuelson, 1981).

\section{ABOUT EBAY}

EBay was incorporated in 1995 and has grown to become the most successful business on the Internet (Cohen, 2002). Within ten years, 430,000 small businesses in the U.S. have opened storefronts on eBay (IBM, 2004). According to EBay's financial reports, its net profit has progressively grown more than tenfold from US\$90,448,000 at end 2001 to US $\$ 1,082,043,000$ at end 2005. On an average day, there are over ten million items listed for sale on eBay. People visit eBay to buy and sell items in thousands of categories from collectibles like trading cards, antiques, dolls, and house wares to practical items like used cars, clothing, books and CDs, and electronics. EBay provides many advantages for buyers and sellers including information on product availability/competition, comparison price points, access to products otherwise unavailable, market-determined price points and entertainment (Bosnjak et al, 2006). Technology driven applications in eBay's website (ebay.com) provides shoppers with a range of evaluation points such as product, price, delivery, and merchant reputation. These applications aid in improving the efficacy and efficiency of the shopper's problem solving and decision making.

\section{THE ECONOMICS OF INFORMATION}

Shoppers traditionally and mainly go to retail stores to do their shopping. Going to the shop involves the concept of 'reach'. Because there are practical limits to the number of shops that a consumer could visit in order to look at the alternative products available for selection, there are limitations to 'reach' (Evans \& Wurster, 1999). 'Richness' refers to the quality of the information available to shoppers (as defined by accuracy, relevance, adequacy etc.), while 'reach' refers to the number of shops that they visit to compare product quality and prices. Within a certain period of time allocated for shopping, the larger the number of shops a shopper visits, the smaller the amount of information the shopper can elicit from any individual store and vice-versa. Evans and Wurster (1999 p.23) state: "To the extent that information is embedded in physical modes of delivery, a basic law governs its economics; there is a universal trade-off between richness and reach." EBay allows shoppers to obtain both richness and reach of information without the tyranny of trade-off. This weakening or elimination of the 'richness/reach' trade-off enables shoppers to browse through a large number of items and stores (a high level of 'reach') to gain a high level of visual, literary, and interactive information (a high level of 'richness'). Consequently, shoppers are able to reap benefits such as the ability to access a wide selection of products without bearing the pecuniary and time costs of travel, and the ability to obtain rich product information for the purpose of more effective decision making. A number of studies report lower buyer search costs on the Internet (e.g. Alba et al, 1997; Bakos, 1997; Brynjolfsson \& Smith, 1999). Shoppers have better price information, leading to tremendous price-competitive pressures on business. That such pressures exist is amply reported (e.g. Evans \& Wurster 1999; Sharma \& Krishnan 
2002). These competitive pressures can be attributed to market contestability implied in Porter's classic model of industry structure analysis (Porter, 1980).

\section{TOWARDS A PERFECTLY COMPETITIVE MARKET}

Traditional markets have asymmetrically distributed information that may experience market failure (Akerlof 1970). EBay is trading platform that greatly improves this distribution by providing complete marketplace information to both buyers and sellers, diminishing the problem of asymmetrical information distribution. This is significant to the extent of a transition from a monopolistic competition market type to a near-perfect market. According to Robert Kuttner in Brynjolfsson \& Smith (2000), 'The Internet is a nearly perfect market because information is instantaneous and buyers can compare the offerings of sellers worldwide. The result is fierce price competition, dwindling product differentiation, and vanishing brand loyalty.'

Many factors in EBay's market suggest key conditions of a near perfectly competitive market. There are low barriers to entry and exit for buyers and sellers in eBay, facilitating to a large number of buyers and sellers. There is no financial cost in registering to buy or sell, and registration can be done with minimal computer knowledge and can be carried out quickly. Information is universally available as buyers can locate all available products and prices using a simple search, creating product homogeneity that renders efforts such as advertising from individual sellers mostly redundant. EBay's simple interface allows sellers to easily list products for sale and provide literary, pictorial, video, and audio information for evaluation. Buyers are able to access all product descriptions and contact all sellers, while sellers are able to obtain the prices and descriptions of their competitor's products. As a result of this information efficiency, prices on eBay are more competitive. Brynjolfsson \& Smith (2000) found that prices were lower on the Internet and that price adjustments by Internet retailers were smaller, which indicates that the Internet market functions more efficiently than traditional markets. Being an electronic medium, transaction costs in eBay are much lower compared to more traditional mediums. Bakos (1997) reported reduced search costs for buyers in an electronic market. These factors suggest perfect information in eBay's marketplace.

\section{MARKET EFFICIENCY FACTORS}

Shoppers are able to search products in EBay using keywords. The system lists all the products on sale according to the relevance of keywords, and allows shoppers to refine the listings according to relevant or matching categories, such as the country where the product/seller is located or sizes for clothing items. Shoppers are able to search for products by clicking on relevant categories which are comprehensively defined. This allows them to instantly locate a specific item from over ten million international product listings available in EBay. Buyer's product guides are available in eBay for a wide variety of items. These guides are written and rated by eBay users, and can help shoppers make a more informed purchase. A link to view the buyer's guide for any particular product that is being searched for is conveniently located within the screen interface.

Prices in eBay can either be dynamic in the form of current bids in auctions, or in the form of a 'Buy It Now' fixed price listings. EBay shoppers are able to search for product listings based on a price range, and sort them from the lowest to the highest price or vice-versa. This enables them to immediately and comprehensively compare all prices among sellers, even delivery costs. An important feature for evaluation is that shoppers are able to obtain a record of the prices in past transactions. This enables shoppers to conceptualize a subjectively fair price to pay or bid for the item. It has been reported (e.g. Moschis, 1976; Brown \& Reingen, 1987) that prices of completed auctions are determined by bidders who comprise a reference group that conveys informational social signals about price/value.

EBay shoppers are able to reach an international market and sort products sold by merchants located within specific geographical areas. For example, shoppers can choose from merchants physically located from 10 to 2000 kilometres of a postcode in a country where eBay operates. This information can be useful if a face-to-face meeting or physical product viewing or testing needs to be arranged, especially for high-involvement products such as cars, boats, and real estate. Location information is also useful for determining delivery cost and time. For shoppers who 
are in urgent need of a certain product, they are able to search listings using a 'get it fast' feature, which refines the search only to product listings that have the option of shipping the item via express post.

EBay shoppers are able to view items for sale by a certain store or merchant in the 'advanced search' section by entering the store name or merchant username. This allows shoppers to view the product offerings of stores and merchants based on their reputation or other users' recommendations. EBay has a reputation rating system that allows registered members (both buyers and sellers) to be rated 'positive', 'neutral', or 'negative'. According to Melnik \& Alm (2005), a seller's overall reputation has a positive and statistically significant impact on a buyer's willingness to pay, and negative comments about a seller often have a negative impact on price. EBay's reputation rating system is highly important as it serves to generate sufficient trust among buyers to persuade them to assume the risk of transacting with complete strangers (Ba \& Pavlou, 2002). This importance of eBay's reputation system is evidenced by its popularity in recent research (e.g. Resnick \& Zeckhauser, 2002; Ba \& Pavlou, 2002; Dellarocas, 2003; Melnik \& Alm, 2005). This rating system plays an important role in making eBay an efficient marketplace because it reduces information asymmetries, as studied by Melnik \& Alm (2005). However, while eBay's reputation system is largely effective, there are ways in which it can be abused. Despite efforts by eBay to make the feedback system tamper-proof, users are able to circumvent the system by registering multiple usernames to make false bids or purchases on his/her own product listings. This enables a particular seller to lodge a positive rating to fraudulently improve his/her overall feedback rating. This also allows the seller to make a 'shill' bid for the purpose of driving the auction price higher or blocking a sale at an insufficiently high price. If eBay successfully implements a way to eliminate tampering of its reputation system, it will then lead to even greater market efficiency.

\section{CONCLUSIONS AND IMPLICATIONS}

The foregoing features of eBay have been explained to increase the quantity and quality of information for consumer problem solving according to Evans and Wurster's (1999) theory of richness and reach in the economics of information. This increased problem solving capability of consumers enabled by features in eBay show that it is moving towards a perfectly competitive marketplace. Previous studies have suggested that the Internet marketplace is more efficient than the traditional marketplace (e.g. Alba et al, 1997; Bakos, 1997; Brynjolfsson \& Smith, 1999). The continuous advancement of technology will inevitably improve such market efficiencies and drive toward a perfect Internet marketplace. This information is expected to be of importance to shoppers and merchants on eBay. For shoppers, understanding the features of eBay will provide more efficient shopping in terms of higher quality information and improved decision making under conditions of minimized bounded rationality.

It is important for businesses that are used to operating in the conditions of monopolistic competition associated with traditional market efficiencies to strategize for the upcoming challenges of near perfect market conditions facilitated by hyper efficient market platforms such as eBay. Marketing strategy formulation can be improved based on an understanding of how eBay creates 'near perfect' market conditions with challenging conditions in the form of lowly dispersed and market driven prices, wide consumer choice, and diminished advertising efforts. This would have implications mainly in the areas of differentiation and positioning strategies by sellers to mitigate the effects of near perfect market conditions. Further research in this area is recommended to empirically verify the significance of eBay's features in consumer problem solving imperatives, which will provide a more complete explanation of how eBay resembles a perfectly competitive market.

\section{AUTHOR INFORMATION}

Dr Joshua Chang is currently an e-commerce lecturer at Charles Sturt University, Australia. Joshua's expertise lies in the area of e-business and retail marketing. He has experience in business consulting and the development of online businesses, including a stock investment forum that was mentioned in the Wall Street Journal and attracted business from corporations such as the Financial Times, Ernst \& Young, and Ericsson. He is the editorin-chief of the Journal of Internet Business, and has published and presented internationally. 


\section{REFERENCES}

1. Akerlof, G. (1970) 'The market for "lemons" Quality uncertainty and the market mechanism', Quarterly Journal of Economics, 84 (3), 488-500

2. $\quad$ Alba, J., Lynch, B., Weitz, C., Janiszewski, R., Lutz, A., Sawyer, S. , \& Wood. (1997) 'Interactive home shopping: Consumer, retailer, and manufacturer incentives to participate in electronic marketplace.' Journal of Marketing 61, 38-53.

3. Au, Y. \& Kauffman, B. (2005) 'Rational expectations, optimal control and information technology adoption', Information Systems and e-Business Management, 3 (1), 17-70

4. Bakos, Y. (1997) 'Reducing buyer search costs: Implications for electronic marketplaces', Management Science, 43(12), 1676-1692.

5. Ba, S. \& Pavlou, P. (2002) 'Evidence of the effect of trust building technology in electronic markets: Price premiums and buyer behaviour', MIS Quarterly, 26(3), 243-268.

6. Bosnjak, M., Obermeier, D., \& Tuten, L. (2006) 'Predicting and explaining the propensity to bid in online auctions: a comparison of two action-theoretical models', Journal of Consumer Behaviour, 5(2), 102-117

7. Brown J. \& Reingen, P. (1987) 'Social ties and word-of-mouth referral behavior', Journal of Consumer Research 14(3): 350-362.

8. Brynjolfsson, E. \& M. Smith. (2000) 'Frictionless commerce? A comparison of Internet and conventional retailers', Management Science, 46 (4), 563-585.

9. Chang, J. \& Samuel, N. (2005) 'Why Purchase Online? An Empirical Study of Australian Internet Shoppers', Journal of Business and Economics, 12

10. Cohen A. (2002) The Perfect Store: Inside eBay. Little Brown \& Company: Boston

11. Dellarocas, C. (2003) 'The digitizaion of word-of-mouth: Promise and challenges of online feedback mechanisms, Management Science, 49(10) 1407-1424

12. Dholakia U. \& Soltysinski K. (2001) 'Coveted or overlooked?: the psychology of bidding for comparable listings in digital auctions', Marketing Letters, 12(3), 225-237.

13. Evans, P. \& Wurster, T. (1999) Blown to Bits: How the Economics of Information Transforms Strategy, Harvard Business School Press, Boston.

14. Gilkeson J. \& Reynolds K. (2003). 'Determinants of Internet auction success and closing price: an exploratory study', Psychology \& Marketing. 20(6), 537-566.

15. IBM (2004) 'eBay supports growing online marketplace with reliable, on demand services.' Case Study Accessed 12 June 2006, found at http://www-306.ibm.com/software/success/cssdb.nsf/CS/SCHS5ZXVGK? OpenDocument\&Site=eserverzseries

16. Melnik, N. \& Alm, J. (2005) 'Seller Reputation, Information Signals, and Prices for Heterogeneous Coins on eBay', Southern Economic Journal, 72(2), 305

17. Moschis, G. (1976) 'Social comparison and informal group influence', Journal of Marketing Research 13(3): 237-244.

18. O'Shaughnessy, J. \& O'Shaughnessy, N. (2005) 'Considerations of Equity in Marketing and Nozick's Decision-value Model', Academy of Marketing Science Review, Vol. 2005, 1

19. Porter, M.F. (1980) 'Industry Structure and Competitive Strategy: Keys to Profitability', Financial Analysis Journal (July/August), 33.

20. Resnick, P. \& Zeckhauser, R. (2002) 'Trust among strangers in Internet transactions: Empirical analysis of eBay's reputation system. M. R. Baye, ed. The Economics of the Internet and E-Commerce', Advances in Applied Microeconomics, 11

21. Riley, J. \& Samuelson, W. (1981) 'Optimal Auctions', American Economic Review, 71(3): 381-392

22. Roth, A. \& Ockenfels, A. (2002) 'Last-minute Bidding and the Rules for Ending Second-price Auctions; Evidence from eBay and Amazon Auctions on the Internet', American Economic Review, 92(4), 10931103.

23. Samuel, N. \& Chang, J. (2005) 'An Economic Model of Consumer Decisions on Online Purchasing: Identification of Research Opportunities' Journal of International Finance and Economics. 2 (1), 75-83

24. Sharma, A. \& Krishnan, R. (2002) 'Clicks Only, Clicks and Bricks, and Bricks Only: Are Retail Salespeople an Important Factor in Choice?', Journal of Marketing Management, Vol. 18, No. 3-4, April. Pp. 317-336.

25. Smith, C. (1989) Auctions: The Social Construction of Value, University of California Press: Berkeley 
26. Stern, B. \& Stafford, M. (2005) 'Individual and social determinants of winning bids in online auctions', Journal of Consumer Behaviour, Vol 5 (1), 43-56

\section{NOTES}

